\title{
OBSERVATION OF AN INTENSE BIOMASS BURNING EVENT OVER SPITSBERGEN Christoph Ritter ${ }^{1}$, Christine Böckmann ${ }^{2}$

\author{
${ }^{1}$ Alfred-Wegener-Institute for Polar and Marine Research, Research Department Potsdam, \\ D-14473 Potsdam, Germany,critter@awi-potsdam.de \\ ${ }^{2}$ University of Potsdam, Institute of Mathematics, Germany
}

\begin{abstract}
During July 2015, an extremely strong event of biomass burning (BB) originating from the boreal America was observed over Spitsbergen with a " $3+2$ " Raman Lidar. In this work we show some results from the lidar and a contemporaneous launched radiosonde to demonstrate that this aerosol was only hygroscopic at humidities above $80 \%$.
\end{abstract}

\section{INTRODUCTION}

The Arctic is climatologically a very sensitive region, where the temperature fluctuations are approximately twice as large as in the global mean, an effect, which is called Arctic Amplification [1]. Especially absorbing aerosol as soot might be important when it acts via radiative forcing in the atmosphere ("dimming") or reducing the albedo via deposition on ground ("darkening").

During summer time the minimal aerosol load is measured in the Arctic [2] with $\mathrm{AOD}_{500}$ values around 0.05 . In Spitzbergen small biogenic particles from the Nordic ocean dominate in in-situ measurements during that season [3], while in remote sensing instruments sporadically BB events can be seen aloft. Due to its location at the edge of the Gulf stream Spitsbergen is a location where generally Arctic and Marine influences mix.

The data of this work was obtained at the research village of $\mathrm{Ny}-\AA$ Alesund, $78.9^{\circ} \mathrm{N}, 11.9^{\circ} \mathrm{E}$, Spitsbergen in the European Arctic. The Alfred-Wegener-Institute for Polar- and Marine research operates several instruments at that site for many years, among others the " $3+2+2$ " Raman lidar KARL ("Koldewey Aerosol Raman Lidar") and daily launches of Vaisala RS-92 radiosondes around $11 \mathrm{UT}$.

On the afternoon of 9 July 2015 the AOD started to increase dramatically, indicating the beginning of the event. Our lidar observations have been performed on $10 \mathrm{July}$, the day with maximal pollution. On that day the $\mathrm{AOD}_{500}$ reached values $>1$. The event lasted for a couple of days in the troposphere and was also recorded by other stations in the European Arctic [4].

\section{DESCRIPTION OF THE EVENT}

The data for this contribution was recorded with the “3+2+2+2” Nd:YAG Raman Lidar KARL. This system was described in [5] and consists of a $70 \mathrm{~cm}$ mirror with approx. $1.5 \mathrm{mrad}$ field of view. It uses a spectra $290-50$ Pro laser with about $10 \mathrm{~W}$ in each color $(355 \mathrm{~nm}, 532$ and $1064 \mathrm{~nm}$ ). Apart from the elastic wavelengths (355 and $532 \mathrm{~nm}$ also in cross polarization) the N2 Raman channels of $387 \mathrm{~nm}$ and $607 \mathrm{~nm}$ and water vapor $(407 \mathrm{~nm}$ and $660 \mathrm{~nm}$ ) were recorded.

The aerosol event was evaluated with a resolution of $30 \mathrm{~m} / 10 \mathrm{~min}$ according to Ansmann [6] using the radiosonde data from our site to correct for the molecular scattering. As the stratosphere was free of aerosol, a backscatter ratio of 1.05 at $532 \mathrm{~nm}$ in $13 \mathrm{~km}-$ $15 \mathrm{~km}$ altitude and an Angström exponent of backscatter of -1 was assumed as a boundary condition. (This is our long-term experience for this site to obtain reasonable color ratios for cirrus clouds and aerosol.) For the following discussion it must be noted that no smoothing was applied to the lidar profiles. Hence it is assumed that each data point with the given resolution has independent information content. Due to the very high extinction and backscatter values the error component due to noise in the data is less than $1 \%$ for the backscatter and about $7 \%$ for the extinction.

The backscatter (at $532 \mathrm{~nm}$ ) and color ratio $(355 \mathrm{~nm} /$ $532 \mathrm{~nm}$ ) of the event is depicted in Figs 1 and 2. It can be seen that the aerosol is mainly confined below $3.6 \mathrm{~km}$ altitude. The structures above $10 \mathrm{~km}$ altitude around UT 12 and in $5 \mathrm{~km}$ altitude in the afternoon are clouds. Times and heights where the backscatter was influenced by multiple scattering have been removed from the figures (white stripes).

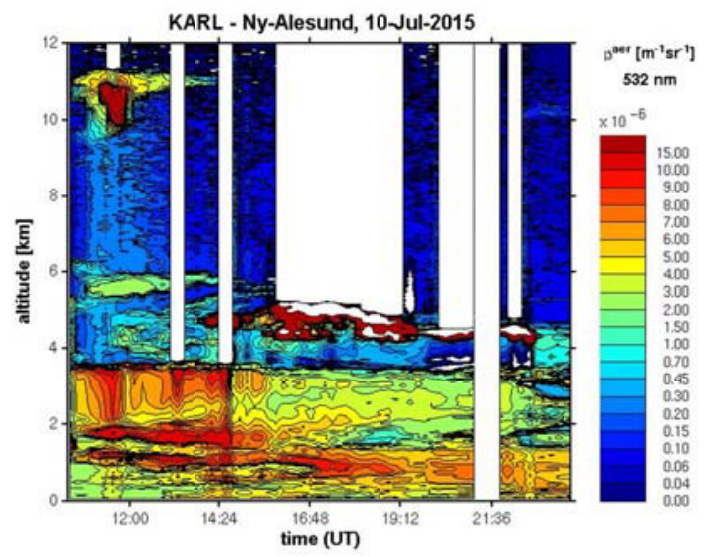


Fig 1: Overview of the backscatter coefficient of the aerosol event.

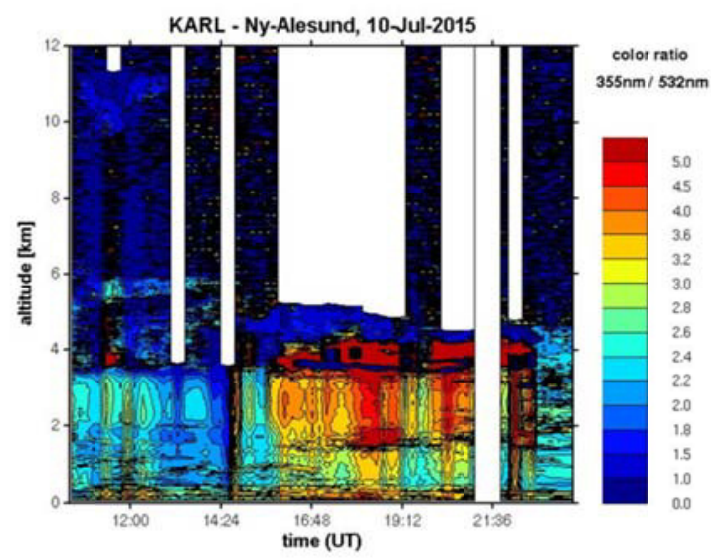

Fig 2: Overview of the color ratio (defined as the ratio of aerosol backscatter at $355 \mathrm{~nm}$ to $532 \mathrm{~nm}$ ) of the aerosol event.

Generally the aerosol load declines over the day and some clear structures and variability is seen in the contour plots.

The origin of the BB event is indicated in Fig. 3 from hysplit trajectories using the NCEP reanalysis data. Very strong forest fires have been reported in Western Canada for the whole month of June [4]. In early July a plume of polluted air was located over Alaska from which the air moved via the North Pole to Spitsbergen within 5 days. Note that due to the sparseness of meteorological data longer trajectories cannot be calculated in the Arctic.

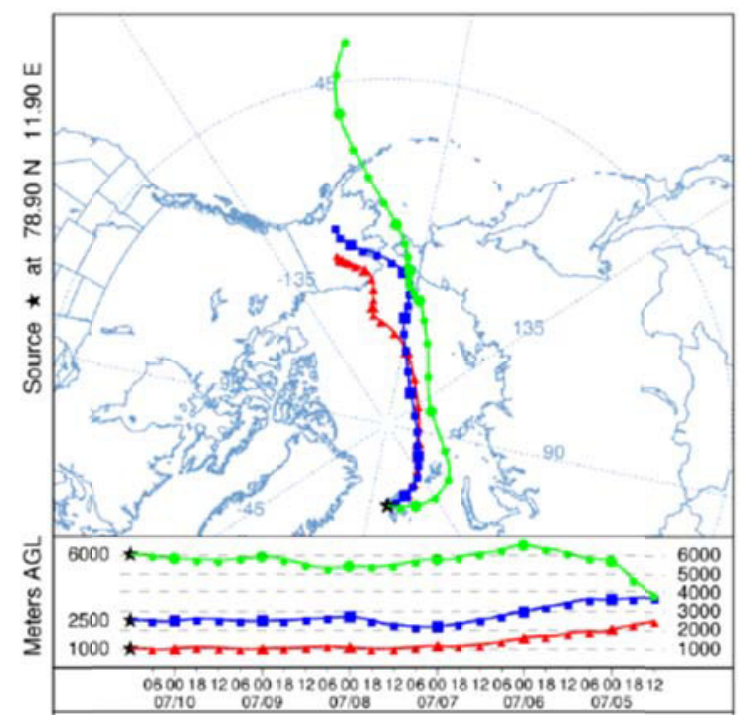

Fig 3: Hysplit backtrajectories with NCEP reanalysis data.
The profile of temperature and contemporary lidar backscatter are plotted in Fig 4. The potential temperature and the relative humidity are depicted in Fig. 5. It can be seen that the stratification is stable in the lowest $2.1 \mathrm{~km}$ altitude (with a very low inversion layer), while between $2.1 \mathrm{~km}$ and $3.5 \mathrm{~km}$ the atmosphere is close to neutral stratified. Nevertheless pronounced gradients both in the humidity and the backscatter exist. For this reason a mixing did not happen as this would have destroyed the gradients. Therefore, by analyzing the aerosol event in detail in altitudes between $2.1 \mathrm{~km}$ and $3.5 \mathrm{~km}$ we can learn something on the hygroscopic properties of this event, as the rel. humidity increased from $50 \%$ to more than $90 \%$. An elevated inversion at $3.5 \mathrm{~km}$ altitude caps the aerosol and the atmosphere becomes much clearer.

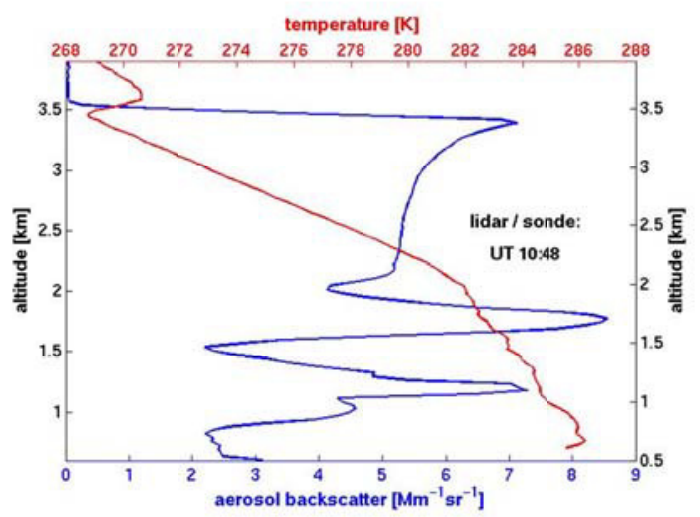

Fig 4: Contemporary profiles of temperature and aerosol backscatter from radiosonde and lidar

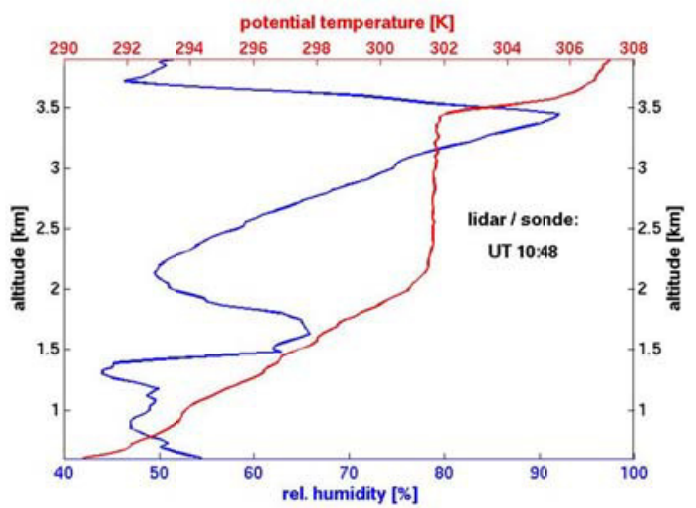

Fig 5: Profiles of potential temperature and relative humidity from the radiosonde 
By inspection of the backscatter coefficient in the interval between 2.1 and $3.4 \mathrm{~km}$ altitude (Fig. 6), which corresponds to an increase of relative humidity from $50 \%$ to $90 \%$, (back-) scattering enhancement factors can be calculated [7], as we assume that the aerosol in this height interval has the same origin. Quite low backscatter enhancements have been found of 1.4 for $532 \mathrm{~nm}$ and $1064 \mathrm{~nm}$ and only 1.2 for $355 \mathrm{~nm}$.

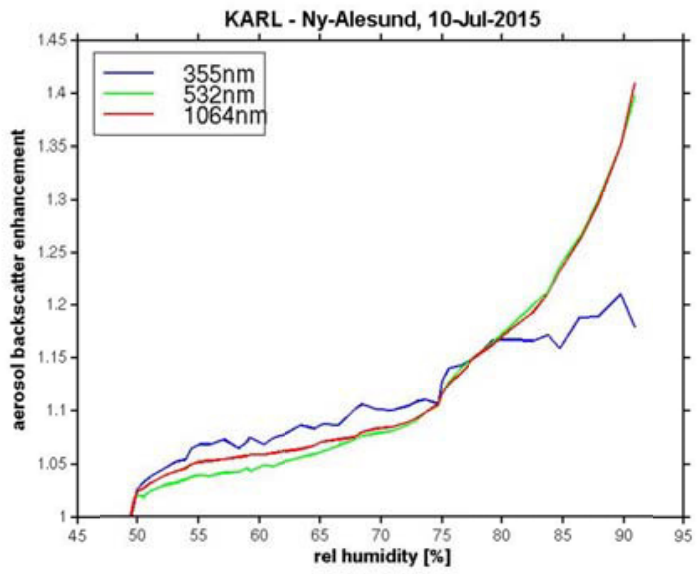

Fig 6: Increase of aerosol backscatter as function of the rel. humidity

To analyze the hygroscopicity of this event further, in Fig. 7 and 8 scatter plots are presented which show the lidar ratios and the color ratios as a function of the relative humidity. In this work we define the color ratio simply by the ratio between the aerosol backscatter of the shorter wavelength divided by the aerosol backscatter of the longer wavelength. Due to the error estimation given above relative changes of the color ratio of $2 \%$ and $8 \%$ for the lidar ratio should be significant.

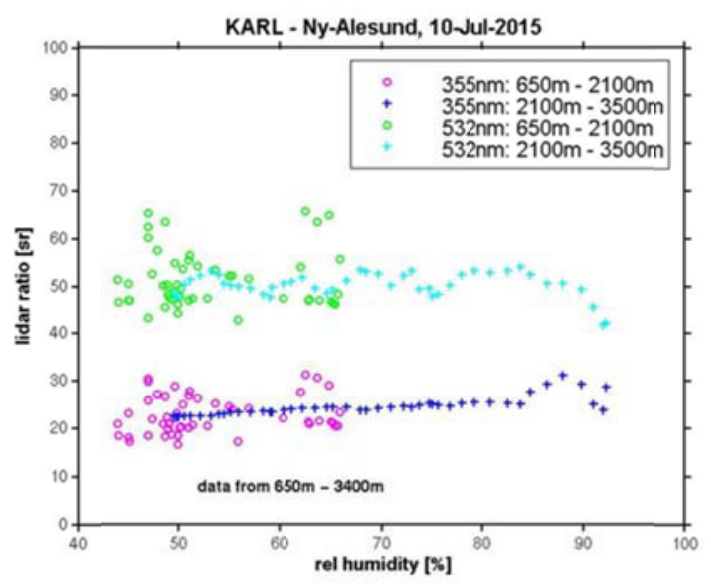

Fig 7: Lidar ratios as function of the rel. humidity
It can be seen from Fig. 7 that the lidar ratios are higher for the visible branch and lower for the UV. The values in both colors are similar to what is found at the site during the Arctic Haze season in spring [8]. Moreover it can be seen that below $2.1 \mathrm{~km}$ altitude the lidar ratios are more variable. In Ny-Ålesund a complex orography of nearby mountains produces generally a complicated wind shear pattern. Only in about $2 \mathrm{~km}$ altitude the wind turns into its synoptic direction, as was analysed be inspection of radiosonde data at the site [9]. Therefore we assume that the aerosol arriving at above $2.1 \mathrm{~km}$ have been in the free troposphere for at least several days, which apparently produced a quite uniform particle distribution. Increasing the relative humidity should lead to water uptake of the aerosol which increases the size and changes the shape and refractive index and, hence, the lidar ratio. However, only a weak influence at humidities $>80 \%$ can be seen, especially at the visible wavelength.

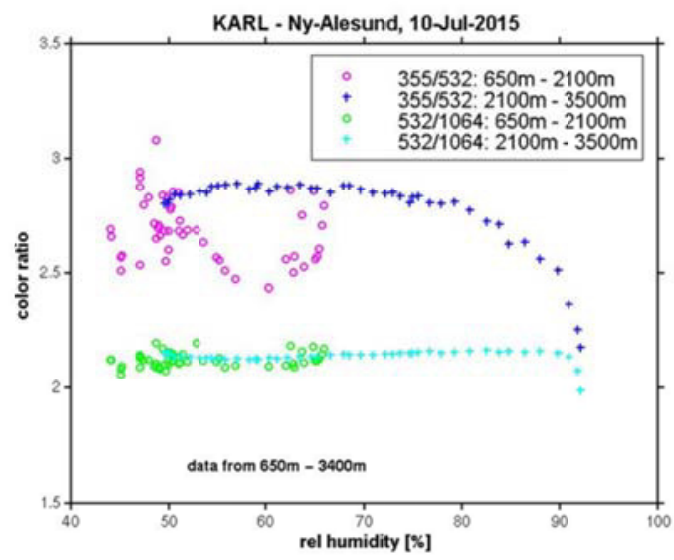

Fig 8: Color ratios as function of the rel. humidity

Fig. 8 shows the dependence of the color ratio on the relative humidity. Again, a higher variability was found in the wind shear zone, whereas in the free troposphere the color ratio is quite uniform up to about $80 \%$ humidity. The color ratio between $532 \mathrm{~nm}$ and $1064 \mathrm{~nm}$ is given in green and cyan. Here a possible hygroscopic growth of the particles is more obvious than in the color ratio of the shorter wavelengths $(355 \mathrm{~nm}$ to $532 \mathrm{~nm})$. In total the hygroscopicity of this BB aerosol seems to be quite low.

Additionally we analysed the linear aerosol depolarisation. The signal induced error for this depolarisation is in the order of $1 \%$. We clearly found higher depolarising particles close to the ground and more spherical aerosol aloft. Apparently the aerosol with complicated geometry seems to sediment down faster and hence is seen closer to the surface in an aged plume. Fig. 8 shows the situation. Also in black the humidity is given for comparison. Above $2 \mathrm{~km}$ there is 
a subtle trend that higher humidity decreases the depolarisation slightly. Nevertheless the depolarisation of this event is mainly a function of the altitude and not of the relative humidity.

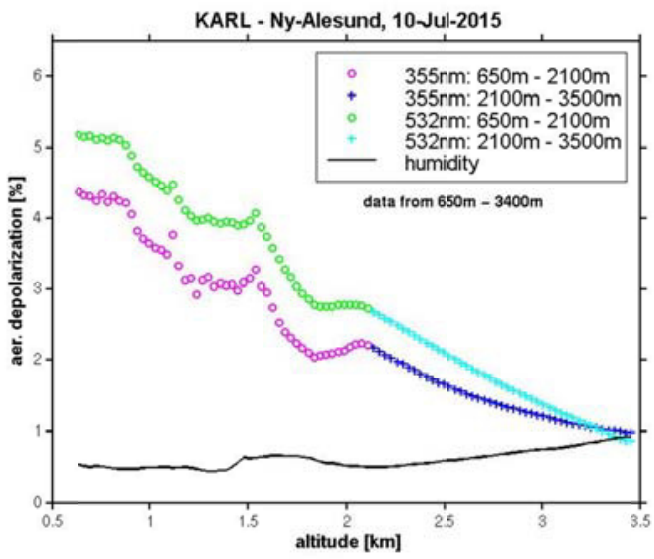

Fig 9: Aerosol depolarization as function of the altitude

\section{SUMMARY AND CONCLUSIONS}

A case study for a BB event in the inner Arctic, which produced an extremely high aerosol load of an aerosol backscatter at $532 \mathrm{~nm}>8 \mathrm{Mm}^{-1} \mathrm{sr}^{-1}$, was presented. The intensive quantities lidar ratio, color ratio and aerosol depolarisation were analysed as a function of humidity measured by a contemporary radio sonde. It was found that the BB event was quite hydrophobic. Only at relative humidities $>80 \%$ a decrease of the color ratio indicated some hydroscopic growth while the influence of the humidity on the lidar ratio was only subtle. The aerosol depolarisation could not be analysed in this way as it clearly increased towards the surface. However, above $1500 \mathrm{~m}$ the depolarisation decreases such that an inversion of the microphysical properties using Mie theory seems to be justified. This will be done in a separate work [10], this conference. Based on the results presented here a refractive index lower than for pure $\mathrm{BB}$ aerosol and an increased particle diameter compared to dry conditions is expected at $3.4 \mathrm{~km}$ altitude where the relative humidity excels $90 \%$.

\section{REFERENCES}

[1] Serrece, M.C. and Francis, J.A.: (2006) The Arctic Amplification Debate, Climate Change, 76, 241 - 264, doi: 10.1007/s10584-005-9017-y

[2] Toledano, C., Cachorro, V.E., Gausa, M., Stebel, K., Aaltonen, V., Berjón, A., Ortiz de Galisteo, J.P., Frutos, A.M., de Bennouna, Y., Blindheim, S., Myhre, C.L., Zibordi, G., Wehrli, C., Kratzer, S., Hakansson, B., Carlund, T., Leeuw, G. de, Herber, A. and Torres, B.: (2012) Overview of sun photometer measurements of aerosol properties in Scandinavia and Svalbard, Atmospheric Environment, 52, 18-28, doi:10.1016/j.atmosenv.2011.10.022

[3] Tunved, P., Ström, J. and Krejci, R.: (2013) Arctic aerosol life cycle: linking aerosol size distributions observed between 2000 and 2010 with air mass transport and precipitation at Zeppelin station, NyÅlesund, Svalbard, Atmos. Chem. Phys. 13, 3643 3660, doi:10.5194/acp-13-3643-2013

[4] Markowicz, K.M., Pakszys, P., Ritter, C., Zielinski, T., Udisti, R., Cappelletti, D., Mazzola, M., Shiobara, M., Lynch, P., Zawadzka, O., Lisok, J., Petelski, T., Makuch, P., Karasinski, G.: (2016) J. Grophys. Res. doi: 10.1002/2016JD025310

[5] Hoffmann, A., Ritter, C., Neuber, R., Beninga, I., Schmid, J.: 2010: A redesigned Raman Lidar for Cloud and Aerosol Profiling in the, ILRC 25, St. Petersburg

[6] Ansmann, A., Wandinger, U., Riebesell, M., Weitkamp, C., and Michaelis, W. 1992: Independent measurement of extinction and backscatter profiles in cirrus clouds by using a combined Raman elasticbackscatter lidar, Appl. Opt. 31, 7113-7113

[7] Granados-Muñoz, M. J., Navas-Guzmán, F., BravoAranda, J. A., Guerrero-Rascado, J. L., Lyamani, H., Valenzuela, A., Titos, G., Fernández-Gálvez, J., and Alados-Arboledas, L. 2015: Hygroscopic growth of atmospheric aerosol particles based on active remote sensing and radiosounding measurements: selected cases in southeastern Spain, Atmos. Meas. Tech., 8, 705-718, doi:10.5194/amt-8-705-2015

[8] Ritter, C. , Neuber, R., Schulz, A., Markowicz, K. M., Stachlewska, I., Lisok, J., Makuch, P., Pakszys, P., Markuszewski, P., Rozwadowska, A., Petelski, T., Zielinski, T., Becagli, S., Traversi, R., Udisti, R. and Gausa, M. (2016): 2014 iAREA campaign on aerosol in Spitsbergen - Part 2: Optical properties from Ramanlidar and in-situ observations at $\mathrm{Ny}$-Ålesund, Atmospheric Environment, 141, pp. 1-19. doi: 10.1016/j.atmosenv.2016.05.053

[9] Schulz, A. (2012) Die arktische Grenzschichthöhe auf der Basis von Sondierungen am Atmosphärenobservatorium in $\mathrm{Ny}$-Ålesund und im ECMWF-Modell, diploma thesis, Univ. Potsdam, https://epic.awi.de/32026/1/Diplomarbeit_Schulz_PBL 2012.pdf

[10] Böckmann, C. and Ritter, C.: Arctic Biomass Burning Aerosol Event - Microphysical property retrieval (this issue) 